\title{
A REVERSE OF YOUNG INEQUALITY
}

\author{
CHANGSEN YANG AND YONGHUI REN
}

Abstract. In this paper, we prove several multi-term refinements of reverse of Young inequality with Kantorovich constant for both real numbers and operators. Among other results, for all $0 \leqslant v \leqslant 1$ and $N \in \mathbb{N},(1-v) a+v b \leqslant(\sqrt{a}-\sqrt{b})^{2}-S_{N}(v ; a, b)+K\left(\sqrt[2^{N}]{h}, 2\right)^{-\beta_{N}(v)} a^{1-v} b^{v}$ for all real numbers $a$ and $b$, where $S_{N}(v ; a, b)$ is a certain function defined by Sababheh. Furthermore, we also improved some inequalities with Kantorovich constant.

Mathematics subject classification (2010): 15A45, 15A60.

Keywords and phrases: Kantorovich constant, Young's inequality, operator inequality, Hilbert-Schmidt norm.

\section{REFERENCES}

[1] M. Sababheh, M. S. Moslehian, Advanced refinements of Young and Heinz inequalities, Journal of Number Theory 172 (2016), 178-199.

[2] Kittaneh, Fuad, Manasrah, et al., Reverse Young and Heinz inequalities for matrices, Linear Multilinear Algebra 59 (2011), 1031-1037.

[3] O. Hirzallah, F. Kittaneh, Matrix Young inequalities for the Hilbert-Schmidt norm, Linear Algebra Its Applications 308, 1 (2000), 77-84.

[4] J. ZhaO, J. Wu, Operator inequalities involving improved Young and its reverse inequalities, Journal of Mathematical Analysis Applications 421, 2 (2015), 1779-1789.

[5] KitTANeh, FuAD, MANASRAH, et al., Improved Young and Heinz inequalities for matrices, Journal of Mathematical Analysis Applications 361, 1 (2010), 262-269.

[6] M. Sababheh, D. Choi, A complete refinement of Young's inequality, Journal of Mathematical Analysis Applications 440, 1 (2016), 379-393.

[7] H. ZuO, G. SHI, M. FuJII, Refined Young inequality with Kantorovich constant (Banach space theory and related topics), Rims Kokyuroku 1753 (2011), 29-34.

[8] Y. Al-Manasrah, F. Kittaneh, Further Generalizations, Refinements, and Reverses of the Young and Heinz Inequalities, Results in Mathematics, 2017: 1-10.

[9] W. LiaO, J. Wu, J. ZhaO, New versions of reverse Young and Heinz mean inequalities with the Kantorovich constant, Taiwanese Journal of Mathematics 19, 2 (2015), 467-479.

[10] H. U. XINGKaI, Young type inequalities for matrices, East China Nor-Mal University, 2012: 12-17.

[11] A. BURQAN, M. KHANDAQJi, Reverses of Young type inequalities, Journal of Mathematical Inequalities 9, 1 (2015), 113-120.

[12] L. NASIRI, M. Shakoori, A Note on Improved Young Type Inequalities with Kantorovich Constant, Journal of Mathematics Statistics 12, 3 (2016), 201-205. 